\title{
Os efeitos da descentralização na gestão da escola pública e no trabalho do diretor em tempos de reforma educacional
}

\section{The effects of decentralization on public school management and the work of the principal in times of educational reform}

\author{
Los efectos de la descentralización en la gestión de las \\ esculas públicas y la labor del director en tiempos de reforma \\ educativa
}

\author{
Luís Gustavo Alexandre da Silva* \\ ORCID: http://orcid.org/0000-0002-5358-9192 \\ Geovana Reis** \\ ORCID: http://orcid.org/0000-0001-9383-591
}

\begin{abstract}
Resumo: O estudo pretende analisar os efeitos do processo de descentralização, em um contexto de reforma educacional, na gestão da escola e no trabalho do diretor no sistema estadual de ensino de Goiás. As análises realizadas têm como referência o documento Pacto pela Educação em Goiás e, os respectivos programas governamentais associados, como o Programa Reconhecer, o Currículo-Referência e o Sistema de Avaliação Educacional do Estado de Goiás (Saego), responsáveis pela efetivação dos princípios da reforma educacional na gestão das escolas públicas estaduais em Goiás. Os procedimentos metodológicos utilizados na pesquisa foram a análise documental, a revisão de literatura e questionários aplicados aos diretores de escolas públicas estaduais. Os resultados mostram que o processo de descentralização desenvolveu-se no sistema estadual de ensino de Goiás, por meio, da diversificação do sistema do ensino efetivada no formato de escolas conveniadas, organizações sociais e escolas militares, bem como pela indução à padronização dos procedimentos de gestão associados à lógica avaliativa e a normatização curricular. Entretanto, a pesquisa demonstra que, ainda não é possível aferir que os procedimentos avaliativos e a padronização curricular, consubstanciadas no Saego e no Currículo Referência, sejam consideradas como as principais referências ou os elementos determinantes da ação pedagógica na gestão da escola.
\end{abstract}

Palavras-chave: Descentralização; Gestão da Escola; Diretor Escolar.

\begin{abstract}
The study aims to analyze the effects of the decentralization process, in a context of educational reform, on school management and on the work of the principal in the state education system of Goiás. The analyses made have as reference the document Pacto pela Educação em Goiás (Pact for Education in Goiás) and, the respective associated governmental programs, such as the Program Recognize, the CurriculumReference and the Educational Evaluation System of the State of Goiás (Saego), responsible for the implementation of the principles of educational reform in the management of state public schools in Goiás. The methodological procedures used in the research were documental analysis, literature review and questionnaires applied to state public school principals.
\end{abstract}

\footnotetext{
* Professor Adjunto da Faculdade de Educação da Universidade Federal de Goiás. Atualmente é coordenador do Núcleo de Estudos e Documentação: Educação, Sociedade e Cultura - Nedesc (2018-2020) e membro do Comitê de Ética em Pesquisa da Universidade Federal de Goiás. E-mail: luis gustavosilva@ufg.br

** Possui mestrado (2002) e doutorado (2015) em Educação Brasileira pela Universidade Federal de Goiás. Atualmente é professora adjunto 3 da Faculdade de Educação da Universidade Federal de Goiás. E-mail: geovanareisufg.br.
} 
The results show that the process of decentralization developed in the state ed- ucation system of Goiás, through the diversification of the education system carried out in the format of partner schools, social organizations and military schools, as well as by inducing the standardization of management procedures associated with the evaluation logic and curricular normatization. However, the research shows that it is still not possible to assess that the evaluation procedures and curriculum standardization, embodied in Saego and the Reference Curriculum, are considered the main references or the determining elements of pedagogical action in school management.

Keywords: Decentralization; School Management; School Director.

Resumen: El estudio tiene como objetivo analizar los efectos del proceso de descentralización, en un contexto de reforma educativa, en la gestión de las escuelas y en la labor del director del sistema educativo estatal de Goiás. Los análisis realizados tienen como referencia el documento Pacto pela Educação em Goiás (Pacto por la Educación en Goiás) y, los respectivos programas gubernamentales asociados, como el Programa Reconocer, el Currículo-Referencia y el Sistema de Evaluación Educativa del Estado de Goiás (Saego), responsable de la aplicación de los principios de la reforma educativa en la gestión de las escuelas públicas estatales de Goiás. Los procedimientos metodológicos utilizados en la investigación fueron el análisis documental, el examen de la literatura y los cuestionarios aplicados a los directores de escuelas públicas estatales. Los resultados muestran que el proceso de descentralización se desarrolló en el sistema educativo estatal de Goiás, mediante la diversificación del sistema educativo llevada a cabo en el formato de escuelas asociadas, organizaciones sociales y escuelas militares, así como mediante la inducción de la normalización de los procedimientos de gestión asociados a la lógica de evaluación y la normalización curricular. Sin embargo, la investigación muestra que todavía no es posible evaluar que los procedimientos de evaluación y la normalización de los planes de estudios, plasmados en Saego y en el Plan de estudios de referencia, se consideren las principales referencias o los elementos determinantes de la acción pedagógica en la gestión de las escuelas.

Palabras clave: Descentralización; La dirección de la escuela; Director de la escuela.

\section{INTRODUÇÃO}

As análises realizadas neste estudo relativas à gestão da escola pública e ao trabalho do diretor escolar, têm como referência o processo de reforma educacional instituído no sistema estadual de ensino de Goiás, por meio do documento Pacto pela Educação e dos respectivos programas governamentais associados, como o Programa Reconhecer, o Currículo-Referência e o Sistema de Avaliação Educacional do Estado de Goiás (Saego), responsáveis pela efetivação dos princípios da reforma educacional na gestão da escola.

O objetivo da pesquisa consiste em identificar os efeitos e consequências da implementação de políticas públicas educacionais articuladas aos parâmetros da reforma educacional, materializadas no sistema estadual de ensino de Goiás, por meio do Pacto pela Educação e dos programas governamentais associados na gestão da escola e no trabalho do diretor. A análise de documentos oficiais da Secretaria de Estado de Educação, Cultura e Esportes de Goiás (Seduce) ${ }^{3}$, como o Pacto pela Educação e o Programa Reconhecer, bem como o Currículo-Referência e o relatório de monitoramento do Sistema de Avaliação Educacional do Estado de Goiás (Saego), é o ponto inicial da investigação. A pesquisa utiliza-se também de revisão de literatura realizada por meio da consulta a bancos de teses e dis- sertações defendidas referente ao processo de reforma educacional em Goiás e a análise sistemática e criteriosa da produção acadêmica realizada na área sobre o tema.

1 A pesquisa analisa documentos elaborados pela Secretaria de Estado de Educação, Cultura e Esportes, no período de 2011 a 2018, assim, é a sigla Seduce que será utilizada no decorrer do texto. No início de 2019, o atual governo renomeou a pasta como Secretaria de Estado de Educação (Seduc-Goiás). 
Além da análise documental e revisão de literatura, os diretores de escolas públicas estaduais foram convidados a responder a um questionário elaborado na Plataforma Forms, com questões de múltipla escolha formuladas a partir de conceitos específicos de investigação provenientes do campo da gestão escolar, da avaliação e do currículo oriundos do processo de revisão de literatura.

A amostra da pesquisa deu-se pela definição de escolas públicas estaduais vinculadas à Coordenadoria Regional de Educação, Cultura e Esporte de Goiânia (Crece-Goiânia)", localizada em Goiânia, na capital do Estado de Goiás, considerada a maior coordenadoria em número de escolas públicas vinculadas e a mais representativa das coordenadorias em comparação com as demais distribuídas no interior do Estado de Goiás. Os questionários foram enviados aos diretores escolares de todas as 131 escolas vinculadas à CreceGoiânia, via e-mail institucional da Seduce, em setembro de 2018, e obteve-se o retorno de 91 questionários. Dessa forma, considerando que se trata de 1 sujeito por escola, a pesquisa contará com uma amostra de 91 participantes diretores escolares, número correspondente ao universo total de representatividade das escolas dessa coordenadoria regional, satisfazendo ao percentual de $95 \%$ de nível de confiança com $6 \%$ de margem de erro.

\section{DESCENTRALIZAÇÃO EM TEMPOS DE REFORMA EDUCACIONAL}

Em geral, o conceito de descentralização associa-se à transferência do poder de decisão política concernente a assuntos relativos aos interesses gerais de órgãos centrais da estrutura burocrática estatal para a dimensão local. A definição desse conceito é perpassada por uma forte conotação polissêmica associada a diferentes perspectivas políticas e ideológicas de organização da sociedade, assim, tanto no campo conservador como no progressista, pode-se identificar uma disputa pela sua apropriação para reafirmar diferentes projetos de sociedade. A princípio, o conceito de descentralização vincula-se à possibilidade de confiar poderes de decisão a instâncias subnacionais dotadas de relativa autonomia. Entretanto, uma leitura mais aprofundada do conceito permite considerar possíveis interfaces e mediações com o poder central, aspecto a ser considerado sob o risco de restringir a análise do conceito a relações de oposição, desconsiderando possíveis relações de complementariedade com a estrutura central (NOVAES; FIALHO, 2010; SOUZA, 2003).

Casassus (1995a) esclarece que o processo de descentralização ou centralização envolve o redimensionamento das estruturas do poder e o reconhecimento de novos atores políticos. Assim, o conceito de descentralização vincula-se não apenas à

\footnotetext{
2 A Secretaria de Estado de Educação, Cultura e Esportes (Seduce), no período de 2014 a 2018, manteve a tradicional estrutura administrativa da Secretaria de Estado de Educação dividida em 40 Coordenadorias Regionais de Educação, Cultura e Esporte (atuais Coordenadorias Regionais de Educação), com o objetivo de melhor distribuir a estrutura burocrática do sistema de ensino. A Coordenadoria Regional de Educação, Cultura e Esporte de Goiânia refere-se a esse órgão vinculado à Seduce responsável pela coordenação de escolas públicas estaduais do município de Goiânia.
} 
possibilidade de confiar poderes de decisão a outras instâncias de poder diferentes do poder central,mas também a democratizar o processo de decisão ao potencializar maior autonomia e representatividade os poderes locais, relativizando a histórica submissão hierárquica aos poderes centrais e com significativo grau de legitimidade política. Na prática, as decisões no campo da descentralização ultrapassam a dimensão técnica para alcançarem o âmbito político relativo às novas configurações do poder, efetivadas por meio da ampliação dos dispositivos capazes de viabilizar maior interferência do poder local (CASSASSUS, 1995b). No campo progressista, a luta pela descentralização, no decorrer da década de 1980, vinculava-se ao fortalecimento das instituições da sociedade civil e a ampliação dos espaços coletivos de decisão, aspectos articulados à afirmação da democracia e da natureza pública das instituições republicanas. O princípio contido na defesa da descentralização era fortalecer as instituições da sociedade civil, visando a constituição de consensos políticos locais e com forte base de negociação para interferir na formulação de projetos na- cionais. A Constituição Federal de 1988 confirma essa perspectiva de descentralização ao instituir maior autonomia aos estados e municípios articulados ao regime de colaboração. Neste sentido, o anseio por um novo paradigma de política e gestão educacional efetiva-se na Carta Magna, em seu artigo 206, que resguarda o princípio da gestão democrática do ensino público. A Lei de Diretrizes e Bases da Educação Nacional corrobora o sentido constitucional ao estabelecer a gestão democrática e regulamentar o seu processo de exe- cução nos sistemas e nos estabelecimentos de ensino (BORDIGNON; GRACINDO, 2000; BRASIL, 2000).

No decorrer da década de 1990, as propostas de descentralização instituídas pelos governos distanciaram-se demasiadamente da conotação democráticopopular materializada na Constituição Federal de 1988, que instituía a educação como direito público e social. Efetiva-se a perspectiva defendida pelo campo conservador que altera o sentido do concei- to, atribuindo o significado de desconcentração de tarefas a uma estratégia de transferência de responsabilidade dos poderes centrais para o nível local sem o devido suporte financeiro necessário para implementação das políticas públicas e, consecutivamente, sem a consti- tuição de efetivos espaços democráticos de decisão capazes de potencializar a participa- ção e dar legitimidade as decisões (SOUZA, 2004).

Segundo Arretche (1996), a efetivação dos princípios democráticos, na implementação de políticas de descentralização, não depende apenas da criação de subsistemas de poder no interior da estrutura, mas associa-se a natureza e as formas de funcionamento das instituições que sejam compatíveis com os princípios democráticos. Nesse sentido, aspectos culturais e sociais constituídos no decorrer da história de formação de uma determinada sociedade interferem na natureza institucional das estruturas de poder.

Salienta-se o processo de disputa e ressignificação do conceito de descentralização no campo da educação, instituído no decorrer da reforma educacional materializada na década de 1990, no Brasil, em que a descentralização deixa de ser compreendida como possibilidade de deslocamento do poder de decisão da esfera central do estado para a dimensão local acompanhada de recursos públicos e do fortalecimento das instituições da 
sociedade civil para um significado restrito à dimensão financeira de repasses e prestação de contas de recursos públicos adicionais transferidos para a instituição escolar articulada a um processo de responsabilização, ou a obtenção de fontes de recursos provenientes de parcerias com o setor privado (MARTINS, 2001).

Nesse contexto, diversas ações e programas foram criados pelo governo federal, visando promover a desconcentração de responsabilidades com o objetivo de transferir, para a esfera local e as escolas públicas, novas atribuições administrativas com recursos financeiros suplementares articulados a parâmetros de responsabilização. Esses programas governamentais, como o Plano de Desenvolvimento da Escola ou o Programa Dinheiro Direto na Escola (PDDE), que atribuem recursos adicionais às instituições escolares, preveem a relativa autonomia financeira da gestão da escola e a institucionalização das Unidades Executoras $^{3}$ de direito privado, responsáveis pela instauração de um padrão de gestão gerencial paralelo à estrutura estatal. Ainda que os programas tenham sido criados a partir de uma política de descentralização de recursos financeiros federais, coube às Unidades Executoras, em especial, aos diretores escolares, a administração dos recursos públicos transferidos pela União e a interiorização da dinâmica de prestação de contas inerente à operacionalização dos recursos contidos nos programas, aspectos que introduziram uma nova dinâmica de gestão na escola, com forte indução ao estabelecimento de parcerias com o setor privado (PERONI; ADRIÃO, 2005).

Essa perspectiva de descentralização articula-se a um projeto maior de reforma do estado conduzido na última década do século $X X$, cujo sentido associa-se a redução do papel e das responsabilidades do estado no provimento da educação pública. Esse paradigma efetiva-se por meio de um amplo processo de redução da estrutura burocrática estatal acompanhada de diminuição dos investimentos públicos e a indução de procedimentos administrativos oriundos do setor privado no cerne da estrutura estatal. $\mathrm{Na}$ prática, essa reorganização da estrutura burocrática estatal com a adoção de dispositivos de gestão do setor privado ou de procedimentos da Nova Gestão Pública tem por objetivo instituir um novo sentido ao conceito de público, vinculando-o à dimensão privada, o que significa a constituição de um estado regulador e avaliador que transfere parte de suas atribuições ao setor privado e à sociedade civil e, concomitantemente, determina ao conjunto do setor público submissão aos parâmetros de eficiência e resultados na gestão como critério para a oferta dos serviços públicos (LAVAL, 2019).

No que concerne o processo de descentralização, o modelo de regulação instituído com a reforma educacional pressupõe a transferência direta de recursos financeiros e do aporte administrativo contido na Nova Gestão Pública para os sistemas de ensino e as escolas públicas.Tais procedimentos tendem a instituir maior responsabilização e controle articulado a parâmetros avaliativos, com efetivas consequências para o amadurecimento de práticas coletivas de discussão pertinente às reais necessidades dos sistemas de ensino e da comunidade escolar.

3 O PDDE define a constituição jurídica de Unidades Executoras (UEx) de direito privado nas escolas públicas como condição para a transferência dos recursos descentralizados. 
O resultado dessa permanente negociação entre os interesses públicos e privados, manifestos por meio das políticas de avaliação e responsabilização sem o devido aporte financeiro e estrutura educativa necessária, é o enfraquecimento do estado como instituição pública capaz de mediar os diversos interesses privados e o fortalecimento da descentralização para o mercado com a constituição de experiências de quase mercados na educação. Um exemplo disso são as escolas charters, financiadas com recursos públicos, mas que operam por contrato de desempenho e pelos vouchers destinados a implementar uma política de competição entre as escolas públicas e privadas, aspectos que tendem a interferir no sentido público inerente à escola e ao processo de formação escolar (KRAW- CZYK, 2005).

Apesar da consistência do parâmetro de descentralização instituído pela reforma educacional sedimentado sobre políticas de responsabilização formuladas em sintonia com procedimentos de avaliação e controle de desempenho, cujo sentido consiste em incitar relações de competição entre os estabelecimentos de ensino e atingir índices de aprendizagem definidos pelas agências de regulação, esse padrão também é perpassado por contradições oriundas de características sociais que configuram, com significativa peculiaridade, o padrão, definindo-o de maneira diferente do modelo original.

Casassus (1995a) esclarece que existem considerações que podem interferir no âmbito do processo de descentralização, dentre elas,

Os processos de descentralização ou centralização estão emoldurados em e dependem das formas históricas de organização do Estado; Os processos de descentralização não devem ser vistos como fluxos que vão em um só sentido, senão que geram movimentos que vão em sentidos contrários; A descentralização administrativa obedece a uma lógica diferente à da descentralização das funções curriculares (p.102).

Isso significa que, apesar da intencionalidade voltada à padronização, o processo de descentralização também sofre significativa interferência do contexto social em que está inserido e as características culturais podem dar novos significados ao modelo definido. Aspectos que podem ser complexos, ao que Barroso (2005) esclarece que, apesar das induções da burocracia estatal e do significativo grau de controle exercido nos sistemas de ensino, por vezes condicionando a adesão dos agentes às políticas formuladas, o estudo sistemático das características sociais e das relações de poder pode determinar certo grau de hibridização nos diversos contextos de aplicação das políticas, aspecto responsável pela potencialização da análise no sentido de capturar as contradições e as singularidades contidas entre o processo de formulação e de efetivação das políticas.

Nesse sentido, compreender em detalhes as características dos sistemas públicos estaduais de ensino mais atingidos pelo processo de reforma educacional, bem como o formato das políticas de descentralização, pode potencializar a análise dos processos educativos com significativa interferência no trabalho realizado pelos diretores escolares tornado ainda mais complexo, sendo obrigados a se adaptarem às orientações gerenciais 
estabelecidas pelos órgãos governamentais, a responder aos compromissos administrativos, distribuir o coletivo escolar na nova estrutura organizacional e submeter a comunidade escolar aos procedimentos avaliativos de desempenho e, ao mesmo tempo, lidar com as contradições relativas à dimensão da gestão e das relações de poder no espaço escolar.

\section{DIVERSIFICAÇÃO E DESCENTRALIZAÇÃO NO SISTEMA ESTADUAL DE ENSINO \\ DE GOIÁS: os programas governamentais em análise}

O processo de reforma educacional em Goiás inicia-se em 2011, com a apresentação do documento Pacto pela Educação: um futuro melhor exige mudanças. Esse documento, lançado no governo de Marconi Perillo (2010-2014), contém diretrizes e orientações concernentes à gestão, ao currículo e ao processo de avaliação realizados na estrutura educacional do sistema estadual de ensino ${ }^{5}$. O Pacto pela Educação efetiva-se como política pública ao instituir uma nova perspectiva teórica responsável pela disseminação de procedimentos e parâmetros articulados aos princípios da responsabilização e da meritocracia na educação pública estadual (GOIAS. SEDUCE, 2011).

Em sintonia com os preceitos teóricos do Pacto pela Educação nos últimos anos, instituiu-se na estrutura do sistema estadual de ensino um intenso processo de diversificação da oferta educacional com a existência de um sistema público associado a convênios com a iniciativa privada. Em 2019, o número de instituições privadas conveniadas com a rede estadual atingiu a cifra de 61 unidades, sendo a maioria dos convênios firmados com instituições especializadas na oferta de educação especial e educação profissional. Salienta-se também a crescente diversificação do sistema de ensino com as organizações sociais responsáveis pela gestão das instituições de ensino profissionalizante, assim como as escolas com padrão militar de gestão, que crescem vertiginosamente no sistema esta- dual de ensino de Goiás. Em 2019, a quantidade de escolas militarizadas atingiu a cifra de 59 instituições distribuídas em 45 municípios goianos (GOIÁS, SEDUC, 2020).

Em relação às características diversificadas do sistema, pode-se destacar que a maioria dos convênios firmados com instituições especializadas na oferta de educação especial e educação profissional constituiu-se com instituições religiosas e/ou filantrópicas. No caso das escolas militarizadas, em parceria com o sistema estadual de ensino, trata-se de um padrão de gestão e currículo escolar baseado na disciplina e na hierarquia militar, adaptado ao perfil e estrutura física das escolas públicas estaduais, modelo instituído, com maior intensidade, entre os anos de 2013 e 2017, por meio de parceria entre o sistema público de ensino e a Polícia Militar, associado à cobrança de taxas de matrículas dos estudantes (GOIÁS, SEDUC, 2020; ALVES; TOSCHI; FERREIRA, 2018).

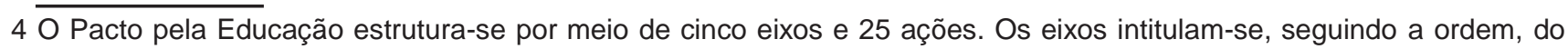
primeiro ao quinto: Valorizar e fortalecer o profissional da educação, Adotar práticas de ensino de alto impacto no aprendizado, Reduzir significativamente a desigualdade educacional, Estruturar o sistema de reconhecimento e remuneração por mérito e Reforma na gestão e na infraestrutura da rede estadual de ensino (GOIAS.SEDUCE, 2011). 
Destaca-se nesse contexto, a tendência de aumento da participação do sistema privado de ensino na oferta de matrículas, com um total de 98.002 distribuídas nos anos finais do ensino fundamental e ensino médio. Se considerarmos o conjunto das etapas da Educação Básica em Goiás, a saber, a Educação Infantil, os Anos Iniciais do Ensino Fundamental, os Anos Finais e o Ensino Médio, o total de matrículas em 2019, no sistema privado de ensino, alcança o número de 278.532 matrículas ${ }^{5}$. O que demonstra uma forte demanda não atendida pelo conjunto do setor público. Esse padrão diversificado no formato de convênios com o sistema público pode assumir diversas configurações, tanto com procedimentos de parcerias subvencionadas pelo governo estadual que não exigem contrapartida direta dos estudantes, como pelo modelo demonstrado no padrão de escolas de gestão militar subsidiadas com recursos públicos e privados, na forma de pagamento das taxas de matrícula (BRASIL, 2019).

Observa-se que as políticas públicas educacionais implementadas por meio do Pacto pela Educação, além de disseminarem a responsabilização e a meritocracia como princípios a serem aplicados na gestão das escolas públicas estaduais, também promoveram a alteração da lógica de funcionamento do setor público com o estímulo a convênios e parcerias com o setor privado. Trata-se de um processo simultâneo de alteração do padrão de gestão e de indução às parcerias no interior da estrutura pública de ensino. Salienta-se que a transferência de parte das responsabilidades educativas do estado para o setor privado, em especial nas modalidades mais onerosas, como a educação especial e o ensino profissionalizante, bem como a indução de procedimentos gerenciais e de semi-privatização na condução dos assuntos educacionais, representa uma grande alteração da dinâmica educativa do sistema de ensino ao instituir parâmetros privados como referência para a condução dos serviços públicos.

Nesse sentido, observa-se também a proliferação de contratos de assessoria pedagógica estabelecidos entre instituições privadas (Instituto Unibanco, Fundação Lemann) e a Seduce, durante a última década, a partir da vigência do Pacto pela Educação, com o objetivo de oferecer suporte pedagógico para a Secretaria Estadual de Educação na oferta de cursos de formação para professores e gestores, fornecimento de material pedagógico, orientação curricular etc. Trata-se de uma estratégia da iniciativa privada de inserção no universo escolar e obtenção de recursos públicos na oferta de serviços de assessoria para os sistemas de ensino com significativos efeitos na gestão dos sistemas e na organização do trabalho docente, cujo sentido é transferir os valores gerenciais e procedimentos privados como referência para a organização das instituições públicas de ensino (SILVA; SAMPAIO, 2015).

\footnotetext{
5 Apenas para compararmos a dimensão do crescimento do sistema privado, de acordo com o Censo Escolar, em 2019, o sistema público registrou, incluindo todos os segmentos e modalidades nas diversas dependências administrativas 1.447.842 matrículas na Educação Básica do Estado de Goiás. Desse total geral, foram matriculados 489.327 alunos na dependência administrativa estadual (BRASIL, 2019).
} 
Com o objetivo de promover na gestão das escolas públicas maior controle e competição entre os agentes escolares, institui-se o Programa Reconhecer (2011) com a adoção de política de bônus salarial. A intenção descrita nas leis que definiram o pagamento de bônus de incentivo aos profissionais da educação era estimular o trabalho de regência de sala de aula e, por esse motivo, previa o pagamento de remuneração adicional aos professores da Educação Básica a partir do critério de assiduidade e de entrega quinzenal do plano de ensino ${ }^{6}$. Nos anos subsequentes à criação do bônus para 0 pagamento do corpo docente, a secretaria estadual de educação definiu para o grupo gestor da escola um índice de acompanhamento da gestão que incluiu, entre outros critérios, o controle do trabalho realizado pelos professores regentes e coordenadores pedagógicos, em especial no que concerne à assiduidade e entrega dos planos de aulas, além de definir como responsabilidade desse grupo, o lançamento da frequência dos profissionais da educação no sistema interno de controle da gestão escolar, aspectos considerados obrigatórios para o recebimento do bônus de incentivo salarial (GOIÁS, 2013).

No tocante aos efeitos do processo de reforma educacional no currículo escolar, os estudos de Matos (2018) revelaram que a formulação do Currículo Referência, destinado a constituir um padrão curricular articulado às diretrizes avaliativas, não contou com a efetiva participação dos professores em seu processo de elaboração. Assim, o documento aparece para os docentes com forte conotação arbitrária e articulada aos procedimentos de avaliação. Segundo a autora, os professores dos anos finais do Ensino Fundamental, em sua grande maioria, não se sentiram representados ou coparticipantes do processo de construção curricular que resultou no documento. Ainda de acordo com a autora, os docentes identificaram o Currículo Referência utilizado no estado de Goiás como um instrumento imposto pela Seduce e elaborado sem a devida participação e construção coletiva necessária envolvendo o conjunto dos professores, o que, segundo eles, retira a autonomia docente e a legitimidade do documento (GOIÁS. SEDUCE, 2012).

Segundo Silva (2018a), o Currículo Referência é um texto curricular prescritivo que se consolida com a cobrança de resultados e índices gerados mediante as avaliações de desempenho. A autora esclarece que a acepção dos docentes se vincula à determinação dos livros didáticos referentes ao conteúdo a ser ministrado no transcorrer de um ano letivo. A proposição dos professores está atrelada ao que é ofertado nos livros didáticos, pois trata-se de um material distribuído nas escolas e de fácil acesso. Além disso, os docentes consideram a sequência do livro a mais adequada, uma vez que reflete as disciplinas dos cursos de graduação e as experiências individuais vividas na educação básica. Os atos de transgressão foram identificados na medida em que as docentes optam por seguir a sequência estabelecida pelo livro didático frente às determinações do Currículo Referência.

6 A partir do ano de 2012, a Seduce-GO ampliou o número de profissionais da educação beneficiados pelo Programa Reconhecer, ao incluir no pagamento do bônus, os coordenadores e coordenadoras pedagógicos, o grupo gestor e os tutores e tutoras pedagógicos. 
De acordo com Silva (2018b), o processo de reforma educacional realizado no sistema estadual de ensino de Goiás centralizado nas avaliações de desempenho, conduziu um movimento intenso de busca de resultados educacionais com consequências diretas nas práticas e relações curriculares. Destaca-se, nesse percurso, a padronização do processo de ensino-aprendizagem e a subordinação das atividades pedagógicas e curriculares às diretrizes definidas em competências e habilidades. Na prática, a organização curricular tem como base os conteúdos definidos nas matrizes de referência das avaliações nacionais e regionais que se instituem como o próprio currículo, aspectos que representam um estreitamento do currículo escolar e redução da autonomia docente na definição das etapas primordiais intrínsecas ao processo de ensino-aprendizagem.

Em relação aos procedimentos avaliativos destaca-se o Sistema de Avaliação Educacional do Estado de Goiás (Saego). O Sistema de Avaliação Educacional do Estado de Goiás, formulado em 2011, se constituiu como a principal referência concernente ao processo de reforma educacional em Goiás e, a partir de seus resultados, foi elaborado diag- nósticos sobre o nível de proficiência dos alunos matriculados na rede estadual de ensino e nas escolas particulares conveniadas (GOIÁS. SEDUCE, 2015).

A pesquisa empírica realizada por Melo (2018) com diretores escolares da rede estadual de ensino de Goiás apresenta a percepção dos dirigentes a respeito das alterações no cotidiano escolar após o crescimento dos procedimentos de avaliação em larga escala instituído nas escolas. O estudo mostra que Índice de Desenvolvimento da Educação Básica (Ideb) provocou mudanças na gestão escolar e que a preocupação dos diretores se concentra em executar ações com vistas a atingir as metas projetadas pelo Instituto Educacional de Estudos e Pesquisas (Inep) e regulada pela Seduce. Na visão dos diretores, as avaliações externas e o Ideb vêm interferindo e repercutindo na gestão escolar da rede estadual de Goiás, pois ao priorizar os conteúdos expressos nas matrizes de referência, bem como no ranqueamento de escolas e nas premiações, a Seduce instaura uma política de responsabilização do diretor quanto ao resultado alcançado por cada escola no ldeb.

Ainda de acordo com Melo (2018), outro aspecto observado na investigação foi o reducionismo curricular imposto por estas avaliações, pois com a instituição das matrizes de referência, estas passaram a direcionar as propostas curriculares das escolas públicas, por terem que trabalhar com os descritores avaliados na Prova Brasil em detrimento às demais áreas do currículo escolar, chegando a adotar e instituir materiais específicos preparados a partir destas matrizes, como vem ocorrendo na rede estadual de ensino de Goiás, com o uso dos Cadernos Aprender Mais e das avaliações propostas: a Avaliação Diagnóstica da Aprendizagem (ADA) e o Sistema de Avaliação do Estado de Goiás (Saego).

Nesse mesmo sentido, Fernandes (2015) esclarece que as políticas educacionais promovidas pela Seduce, em especial por meio do Pacto pela Educação e do Saego, baseadas em avaliações de larga escala e em resultados, promovem um esvaziamento do currículo escolar ao estabelecer a padronização das relações de ensino aprendizagem 
com base em competências e habilidades. Segundo a autora, as consequências são prejudiciais aos professores, que têm sua autonomia pedagógica comprometida com efeitos diretos sobre a profissionalização docente, uma vez que o trabalho dos professores restringe-se a um ensino por memorização e treinamento para responder testes padronizados, e aos alunos, que têm o processo de ensino-aprendizagem restrito a preparação para a realização de testes sistêmicos.

A proposta educativa promovida pelo Saego corrobora a concepção de educação sedimentada na avaliação de desempenho e edifica essa perspectiva na condução dos processos pedagógicos com significativa consequência para a gestão da escola, em especial para o trabalho do diretor responsável pela implementação das políticas educacionais e incumbido de gerir os conflitos de interesses entre os diversos agentes existentes no cotidiano escolar.

\section{AS CONTRADIÇÕES NA GESTÃO DA ESCOLA E NO TRABALHO DO DIRETOR DECORRENTES DOS PARÂMETROS DE DESCENTRALIZAÇÃO, CURRÍCULO E AVALIAÇÃo PROPOSTOS NO PACTO PELA EDUCAÇÃO E NA REFORMA EDUCACIONAL EM GOIÁS}

As análises realizadas neste tópico têm como referência as respostas dos 91 diretores escolares ao questionário aplicado aos dirigentes de escolas públicas estaduais pertencentes à Seduce e vinculadas à CRECE-Goiânia, destacando-se as partes do questionário cujo objeto de investigação foram o programa Reconhecer, o Currículo Referência, a ADA, o Saego e seus efeitos sobre a gestão da escola.

As respostas afirmativas da maioria dos diretores escolares em relação à intensificação do controle e do monitoramento do conjunto dos professores, realizado pelo grupo gestor da escola como cumprimento das orientações previstas no programa Reconhecer, demonstra que houve alguma interferência na gestão da escola por parte desse dispositivo de controle associado ao pagamento de bônus. Em especial, pela razão de que acompanhar a assiduidade e a entrega quinzenal do plano de ensino dos professores é o principal critério para o pagamento do bônus do próprio grupo gestor da escola. Salienta-se que, em relação ao número de docentes e ao tipo de vínculo empregatício dos professores vinculados ao sistema estadual de ensino, quase a metade do total de professores, 9.356, são contratados ou possuem vínculos empregatícios precarizados, aspecto que pode interferir na submissão de parte significativa dos professores à lógica da bonificação (BRASIL, 2019).

Em relação ao Currículo Referência, ao serem questionados sobre a participação dos agentes escolares na elaboração do Currículo Referência, a maioria absoluta dos diretores declara que foi a equipe técnica da Seduce que assumiu o protagonismo no processo de elaboração do documento curricular, afirmação contestada apenas por um grupo de 20 diretores, que afirmam terem sido os professores. Trata-se de um componente relevante identificar os agentes escolares protagonistas e o respectivo grau 
Os efeitos da descentralização na gestão da escola pública...

de participação no processo de discussão e elaboração do Currículo Referência, pois a implementação de um novo currículo depende de convergências e acordos que envolvem os diferentes agentes, capazes de estimular alterações nas práticas escolares.

No que concerne à forma como o Currículo Referência mais interfere na realização do trabalho pedagógico do professor, a maioria dos diretores afirma que o Currículo define os conteúdos a serem ensinados pelo professor e como vinculá-los a avaliações de desempenho (Saego), bem como estabelece a sequência do que deve ser ensinado e a metodologia de trabalho a ser usada pelo professor. Assim sendo, o diretor identifica que a estrutura do Currículo Referência interfere na autonomia do professor em definir a sequência didática, as estratégias de ensino-aprendizado e o ritmo de condução do processo de aprendizagem. Quanto à execução do trabalho do diretor, o Currículo Referência interfere ao passo que obriga o diretor a monitorar 0 trabalho dos coordenadores em relação ao acompanhamento dos professores, responsabilizando o diretor a fornecer condições de trabalho adequadas para que o currículo seja executado, além de controlar se o professor está ou não aplicando o currículo.

Em relação às principais interferências da implementação do Currículo Referência na gestão pedagógica da escola, destacam-se, segundo os diretores, a padronização dos conteúdos e do processo de ensino-aprendizagem, a introdução de uma gestão mais preocupada com a sistematização dos conteúdos e a aferição do currículo aplicado em avaliações de desempenho escolar. Na prática, o Currículo Referência tende a padronizar, sistematizar e definir a ordem sequencial dos conteúdos, bem como a associar os processos de aprendizagem realizados diretamente pelo professor em sala de aula e a estrutura avaliativa definida pela Seduce, como o Saego e a ADA.

Ao serem questionados a respeito da interferência da ADA na organização da gestão pedagógica da escola, os diretores afirmam que a ADA interfere por definir mais atividades de planejamento em Matemática, Português e Ciências, determinar o foco dos processos de aprendizagem nos conteúdos da avaliação da ADA e por definir maior preocupação dos coordenadores pedagógicos com os resultados alcançados na ADA. De fato, os dados demonstram a presença do currículo articulado a mecanismos de avaliação na gestão pedagógica, induzindo os agentes escolares a sistematizarem os conteúdos e subordinarem a condução dos processos educativos aos procedimentos de avaliação.

A ADA interfere na aplicação do Currículo Referência, segundo a maioria dos diretores, ao determinar os conteúdos do novo currículo que devem ser efetivamente aprendidos pelos alunos; fortalecer uma lógica comum entre os professores de aplicação dos conteúdos articulados ao Currículo Referência e a posterior avaliação bimestral; e controlar os conteúdos que realmente foram trabalhados pelo professor em sala de aula, aspectos que demonstram significativa articulação entre os procedimentos avaliativos e o currículo aplicado em sala de aula. Aspectos que podem representar significativa restrição do potencial formativo do currículo, condicionado as demandas avaliativas e as limitações das experiências educativas vivenciadas pelos alunos, em razão da menor autonomia do professor no processo de ensino-aprendizagem (FREITAS, 2018). 
No tocante as principais críticas dos professores à ADA, a maioria dos diretores descreve o volume exagerado de avaliações, a cobrança por resultados, o foco nas avaliações, a intensificação do trabalho do professor e as restrições na autonomia do trabalho pedagógico. No entanto, um grupo de 26 participantes afirma o contrário, que não houve críticas à ADA. Na prática, os diretores tendem a minimizar a existência de críticas aos programas governamentais e aos procedimentos de gestão conduzidos na escola, mas, em geral, eles têm que gerir conflitos com os professores, em especial no campo administrativo, com o excesso de monitoramento e no campo pedagógico, com a perda da autonomia decorrente dos instrumentos de avaliação.

Neste sentido, essa indução à aceitação dos princípios avaliativos e da regulação gerencial na gestão da escola promovida pela Seduce pode ser melhor compreendida ao se analisar a concordância da maioria absoluta dos diretores à afirmação de que os resultados do Saego representam um instrumento de monitoramento e avaliação do trabalho realizado por eles na escola. Todavia, quando questionados se o monitoramento do Saego implica em limitações da autonomia pedagógica da escola, a maioria dos diretores discorda da afirmação. Isso revela que há contradições entre as orientações e mecanismos de controle oriundos da Seduce e a dinâmica da escola. Apesar da interferência dos aspectos avaliativos, como constatados nos dados, também é possível inferir que a escola opera, ainda, com uma restrita margem de autonomia pedagógica, e que os procedimentos avaliativos, apesar da constante indução dos programas governamentais, não conseguem adentrar em determinadas dimensões da ação educativa realizada no cotidiano escolar.

Nesse sentido, segundo os diretores, as principais dificuldades do professor para aplicar o Currículo Referência nas escolas referem-se à distância entre o proposto no currículo e o livro didático, a dificuldade em seguir a estrutura de conteúdo, a lógica de desenvolvimento de competências/habilidades e a sequência didática mais sistematizada, bem como o volume de conteúdos e a reduzida autonomia para reforçar determinados conhecimentos. As respostas dos diretores em relação a distância entre o proposto pelo novo currículo e a estrutura do livro didático revela dificuldades de operacionalização do Currículo Referência, pois a estrutura sequencial dos conteúdos definida no Currículo Referência, muitas vezes, não coincide com a perspectiva didático-teórica ou com a própria estrutura de conteúdos dos livros didáticos. Outro aspecto relevante, trata-se da dificuldade em seguir a estrutura bimestral de conteúdos e a sequência didática definida pelo Currículo Referência, devidamente articuladas aos parâmetros avaliativos, o que representa na prática, a restrição da autonomia do professor concernente à definição do ritmo de aprendizagem e do reforço de conhecimentos e conceitos com os alunos.

Esses dados demonstram que houve problemas no processo de operacionalização do Currículo Referência nas escolas. Na prática, tais situações tendem a revelar que os professores não foram devidamente envolvidos no conjunto do processo de elaboração e implementação do novo currículo no sistema estadual de ensino, por não terem sido consultados ou por suas conclusões sobre a aplicação do Currículo Referência não terem 
Os efeitos da descentralização na gestão da escola pública...

sido devidamente consideradas, pois a incompatibilidade entre as demandas do novo currículo e a estrutura dos livros didáticos, ou as dificuldades dos professores em trabalhar com competências e habilidades, demonstram a ausência de acordos entre os agentes envolvidos.

\section{CONSIDERAÇÕES FINAIS}

Os estudos realizados permitiram identificar como o Reconhecer, o Currículo Referência, a ADA e o Saego articulam-se em torno de um projeto educativo com significativa interferência na gestão da escola pública e no trabalho do diretor escolar. Nesse sentido, os dados da pesquisa revelam que os procedimentos curriculares tendem a padronizar, sistematizar e definir a ordem sequencial dos conteúdos a serem trabalhados nas escolas, em sintonia com a estrutura avaliativa definida pela Seduce e efetivada por meio da ADA e do Saego. Aspectos que demonstram o processo de transferência para a escola pública de responsabilidades avaliativas e curriculares, visando padronizar os procedimentos escolares submetendo-os a lógica de regulação definida pela reforma educacional.

Trata-se de um processo de descentralização que promove tanto a diversificação do sistema do ensino por meio de escolas conveniadas, organizações sociais e escolas militares, como pela indução à padronização dos procedimentos curriculares e avaliativos visando a interiorização desses valores pelos agentes escolares, próprios de um modelo de educação pautado pelos princípios da eficiência, da competitividade e dos resultados educacionais. Elementos essenciais para transferir as responsabilidades educacionais para os próprios agentes escolares, instituir um padrão de competitividade e classificação entre as escolas públicas e privadas e criar um modelo de quase-mercado na educação.

Entretanto, a pesquisa também demonstra que ainda não é possível aferir que os procedimentos avaliativos, consubstanciados no Saego, sejam considerados pelos agentes escolares como objeto principal da ação pedagógica nas escolas. Os dados revelam que a maioria absoluta dos diretores concorda com a afirmação de que os resultados do Saego representam um instrumento de monitoramento e avaliação do trabalho realizado por eles na escola. Portanto, há pressão sobre os diretores para seguirem as orientações. Todavia, quando questionados se o monitoramento do Saego implica em limitações a autonomia pedagógica da escola, a maioria dos diretores discorda da afirmação, o que revela que há contradições entre as orientações e mecanismos de controle oriundos da Seduce e a dinâmica da escola.

Esse contraditório contexto situado entre a tentativa de disseminação de uma cultura de avaliação e uma perspectiva de descentralização consubstanciada, por meio de políticas educacionais formuladas sobre a lógica de resultados de aprendizagem, defronta-se com as contradições próprias da natureza do trabalho pedagógico e das práticas coletivas dos professores, dimensões que precisam ser melhor analisadas em seus diferentes níveis e graus de intervenção na gestão da escola e no ambiente escolar, 
pois a análise das contradições existentes no intervalo entre a proposição e a implementação de políticas educacionais nas escolas, e a assimilação e internalização dos princípios na condução do processo educativo, contém aspectos fundamentais capazes de elucidar possibilidades de formulação de novas estratégias de ação pedagógica articuladas à retomada de princípios democráticos, no campo da avaliação e da gestão, coerentes com perspectivas de educa- ção mais críticas e abrangentes. 


\section{REFERÊNCIAS}

ALVES, Miriam Fábia; TOSCHI, Mirza Seabra; FERREIRA, Neusa Sousa Rêgo. A expansão dos colégios militares em Goiás e a diferenciação na rede estadual. Retratos da Escola, v. 12, n. 23, p. 271-288, 2018.

ARRETCHE, Marta T. S. O mito da descentralização: maior democratização e eficiência das políti- cas públicas. Revista Brasileira de Ciências Sociais. São Paulo. v. 11, no 31, p. 44-66, 1996.

BARROSO, João. O Estado, a Educação e a regulação das políticas públicas. Educação \& Socie- dade. Campinas, vol. 26, n. 92, p. 725-751, Especial, Out. 2005.

BORDIGNON, Genuíno; GRACINDO, Regina Vinhaes. Gestão da educação: o município e a esco- la. In: FERREIRA, Naura Syria Carapeto; AGUIAR, Márcia Ângela (Orgs).

Gestão da educação: impasses, perspectivas e compromissos. São Paulo: Cortez, 2000.

BRASIL [1988]. Constituição da República Federativa do Brasil. 05 de Outubro de 1988. Brasí- lia: Senado Federal, Subsecretaria de Edições Técnicas, 2000.

BRASIL. MEC. INEP. Sinopse Estatística da Educação Básica. Brasília, 2019. Disponível em: http://portal.inep.gov.br/sinopses-estatisticas-da-educacao-basica. Acesso em: 10 mar. 2020.

CASASSUS, Juan. Tarefas da educação. São Paulo: Autores Associados, 1995a.

Cadernos de Pesquisa. São Paulo, no 95, p. 37-42, nov. 1995b.

FERNANDES, Silvia Reis. Concepções e práticas vigentes em escolas públicas: a influência das políticas educacionais no trabalho dos professores.2015. 108f. Dissertação (Mestrado) - Pon- tifícia Universidade Católica de Goiás, Programa de Pós-Graduação Stricto Sensu em Educação, Goiânia, 2015.

FREITAS, Luiz Carlos. A reforma empresarial da educação: nova direita, velhas ideias. São Pau- lo: Expressão Popular, 2018.

GOIÁS. SEDUC. Site oficial da Secretaria de Estado de Educação. Escolas detalhadas. Dispo- nível em: https://site.seduce.go.gov.br/pesquisa-de-escolas-detalhada/. Acesso em: 21 mar. 2020.

GOIÁS. Lei no 18.093, de 17 de Julho de 2013. Institui, para o ano de 2013, o Bônus de Incentivo Educacional aos profissionais da educação pública estadual e dá outras providências. Goiânia, 2013.

GOIÁS. SEDUCE. CAEd. Revista do Sistema de Avaliação. SAEGO. Universidade Federal de Juiz de Fora, Faculdade de Educação, Juiz de Fora, 2015. Disponível em http://www.saego.caedu- fjf.net/ Acesso em: 08 fev. 2019.

GOIAS. SEDUCE. Pacto pela Educação: um futuro melhor exige mudanças. 2011. Disponível em: http://www.seduc.go.gov.br/especiais/pactopelaeducacao/docs/Microsoft PowerPoint Acesso em: 08 fev. 2019. 
GOIAS. SEDUCE. Currículo Referência da Rede Estadual de Educação de Goiás. 2012. Dispo- nível em:

http://www.seduc.go.gov.br/imprensa/documentos/arquivos/CurriculoReferencia/CurriculoReferenciadaRedeEstadualdeGoias.pdf Acesso em: 08 fev. 2019.

KRAWCZYK, Nora. Políticas de regulação e mercantilização da educação: socialização para uma nova cidadania? Educação \& Sociedade. Campinas, vol. 26, no 92, p. 799-819, Especial - Out. 2005.

LAVAL, Christian. A escola não é uma empresa: o neoliberalismo em ataque ao ensino público. São Paulo: Boitempo, 2019.

MARTINS, Ângela. A descentralização como eixo das reformas do ensino: uma discussão da litera- tura. Educação \& Sociedade. Ano XXII, nº 77, Dezembro/2001.

MATOS, Milena de Oliveira. O Currículo e o seu papel no ensino: compreensão de docentes de Ciências da Natureza do Ensino Fundamental II das Escolas Estaduais em Goiânia. 2018. 122f. Dissertação (Mestrado) Programa de Pós-Graduação em Educação em Ciências e Matemática - Universidade Federal de Goiás, 2018.

MELO, Viviane Pereira da Silva. Avaliação em larga escala: repercussões do IDEB na visão dos diretores de escola da rede estadual de Goiás. 2018. 182 f. Dissertação (Mestrado). Programa de Pós-Graduação em Educação - Faculdade de Educação da Universidade Federal de Goiás, Goiâ- nia, 2018.

NOVAES, Ivan Luiz; FIALHO, Nadia Hage. Descentralização educacional: características e pers- pectivas. RBPAE. v.2, ํㅜ 3, p. 585-602, set./dez. 2010.

PERONI, Vera; ADRIÃO, Thereza. Público não-estatal: estratégias para o setor educacional brasi- leiro. In: PERONI, Vera; ADRIÃO, Thereza (Orgs). O público e o privado na Educação: interfaces entre Estado e sociedade. São Paulo: Xamã, 2005.

SILVA, Ana Paula Gomes Vieira. O Currículo Referência da rede estadual de educação de Goiás: implicações nas atividades de professores de Ciências. 2018. 150f. Dissertação (Mestrado). Programa de Pós-graduação em Educação em Ciências e Matemática. Universidade Federal de Goiás. Goiânia, 2018a.

SILVA, Simônia Peres. Reforma Educacional goiana: desdobramentos no currículo e nas práticas educativas. In: LIBÂNEO, José Carlos; FREITAS, Raquel A. Marra Madeira (Orgs.) Políticas edu- cacionais neoliberais e escola pública: uma qualidade restrita de educação escolar. Goiânia: Editora Espaço Acadêmico, 2018b.

SILVA, Luís Gustavo A; SAMPAIO, César Luis. Trabalho e autonomia do coordenador pedagógico no contexto das políticas públicas educacionais implementadas no Estado de Goiás. Ensaio: Aval. Pol. Educ. [Online]. 2015, vol.23, n.89, pp.964-983.

SOUZA, Ângelo. Reformas educacionais: descentralização, gestão e autonomia escolar. Educar, Curitiba, n. 22, p. 17-49, 2003.

SOUZA, Donaldo Bello; FARIA, Lia Ciomar Macedo. Reforma do Estado, Descentralização e Muni- cipalização do ensino público no Brasil: a gestão política dos sistemas públicos de ensino pós-LDB 9.394/96. Ensaio. Aval. Pol. Educ. Rio de Janeiro, v. 12, no 45, p. 925944, out./dez. 2004. 